\title{
Overwinter survival and post-release movements of translocated water voles: implications for current mitigation guidance
}

\author{
R. Baker \& D. M. Scott \& C. Keeling \& C. Dwight
}

\begin{abstract}
Translocation is currently used as a last resort mitigation strategy for water voles (Arvicola amphibius) in the UK (Dean et al. 2016, The Water Vole Mitigation Handbook), where populations have undergone widespread declines during the past century Q214 (Strachan and Jefferies1993, Preliminary report on the changes in the water vole as shown by the National Surveys of1989-1990 and 1996-1998). To increase the chances of success, current guidance suggests translocation of voles during autumn should not be carried out as individuals may be at higher risk of overwinter mortality, and instead should be overwintered in captivity for release the following spring (Dean et al. 2016). To verify this guidance, we carried out a mark recapture and radio tracking study of an autumn translocated and resident population in lowland England. Whilst we found translocated voles undertook longer exploratory movements than residents and those previously recorded in spring, there was no evidence from our study that translocated voles suffered higher mortality rates compared to the resident individuals. The turnover in both populations was high with $25 \%$ and $8 \%$ of the translocated and resident individuals being recaptured in spring. Younger voles that were not collared had a significantly higher chance of being recaptured in spring and their survival and settlement on the receptor channel is considered important as this is the age class that will produce most of the following years' young. Mean weekly distances moved by collared voles showed no pattern of stabilisation, in either sex, over the 10-week monitoring period and combined dispersal from both study populations accounted for $26 \%$ of those that were not recaptured in spring. However, due to low sample size, we were unable to distinguish between the effects of dispersal and mortality. We conclude that where individuals or populations will be negatively impacted by planned development, autumn translocations in lowland England may offer a feasible alternative to housing animals in captivity, given the high financial cost and additional health and welfare risks associated with a captive environment. The receptor site and adjacent habitat (> $1 \mathrm{~km}$ ) would need to support a seasonal abundance of food and cover, be connected to existing populations and be part of a wider landscape that is mink free and under an effective mink control programme to help secure long-term population viability. We advise, however, that due to our small sample size, further studies are undertaken to confirm our findings.
\end{abstract}

Keywords: Arvicolaamphibius, Radiotracking, Mitigation, Survival, Translocation, Watervole 


\section{Introduction}

Wildlife translocation is an established technique for species conservation and is primarily used to re-establish viable populations of species of conservation concern (IUCN 1998). More recently, however, translocations are becoming increasingly used as a mitigation measure to avoid the adverse effects that developments and other landscape change have on populations of threatened species (Germano et al. 2015). They typically involve the relocation of individuals of a protected species from permitted building and development sites in order to preserve populations and meet the relevant legislative requirements for species protection, an example being species listed under The Habitats Directive (European Union Council Directive 92/43/EEC) which applies across all European member states. For ecological consultants and land managers, this form of mitigation is clearly of value as it offers a plausible strategy for dealing with protected species that would otherwise be inadvertently killed as a result of habitat destruction.

Translocations, however, do not always work in the way they were intended as individuals can stray far away from the release site and/or suffer high mortality rates after their release into a novel environment (Moehrenschlager and Macdonald 2003; Le Gouar et al. 2008; Berger-Tal and Saltz 2014). This can be due to a myriad of factors including (a) the suitability of the receptor site, e.g. availability of food and shelter and abundance of predators; (b) the method and timing of release, e.g. hard or soft release; and (c) the number, composition and health of relocated individuals (Fischer and Lindenmayer 2000; Armstrong and Seddon 2008; IUCN/SSC 2013). Although post-release dispersal can aid in connectivity between existing populations, such as species that conform to a metapopulation structure, both dispersal and mortality are considered key processes that can lead to local population extinction and translocation failure (Armstrong and Seddon 2008). To increase the chances of success, most translocations are designed and undertaken in line with the IUCN guidelines (IUCN/SSC 2013) and will follow best practice guidance that is underpinned by ecological knowledge of the species and/or previous reintroduction/relocation attempts. However, the outcomes of translocations delivered for mitigation purposes are rarely reported (Germano and Bishop 2008), leading to the effectiveness of guidance being largely unrealised. With many countries, including the UK, US and Australia, now using translocations for mitigation purposes (see Germano et al. 2015 for a review on mitigation-driven translocations), there is an urgent need for follow-up monitoring to be reported in order to advance the effectiveness of translocation as a mitigation solution.

In the UK, water voles (Arvicola amphibius) are one of several protected species for which translocation to on- or off-site receptor sites is considered a mitigation option to avoid the unintentional killing or injury of animals, as stipulated by their full protection under Schedule 5 of the Wildlife and Countryside Act (1981) (Strachan et al. 2011). Following their widespread decline in the UK due to habitat loss and predation by feral American mink (Neovison vison) (Jefferies et al. 1989; 
Strachan and Jefferies 1993; Strachan et al. 2000), translocations must be carried out under licence, show a demonstrable benefit to the species and be delivered in line with IUCN guidance (IUCN/SSC 2013). Previous mitigation strategies have relocated water voles into new on-site receptor habitat during temporary river works (Strachan et al. 2011) and translocated individuals have been used to establish a new population (Mathews et al. 2006; Gow et al. 2012). The success of these, and translocations in general, is based on the persistence of a viable breeding population that is either large enough to be self-sustaining or is linked to other colonies (Strachan et al. 2011).

To help deliver successful outcomes of mitigation translocations, "best practice" guidance has been developed for water voles in the UK (Dean et al. 2016). This guidance suggests that translocation during autumn (15 September-30 November, inclusive) should not be undertaken due to a higher risk of overwinter mortality and, alternatively, animals should be overwintered in captivity for release the following spring (Dean et al. 2016). This recommendation is based on ecological knowledge and available accounts of previous translocation and reintroduction attempts (Mathews et al. 2006; Moorhouse et al. 2009; Strachan et al. 2011; Gow et al. 2012). Research involving a phased release (May-July) of 147 translocated and captive-bred water voles, for instance, found from recapture data that earlier released individuals had a higher initial survival (autumn of the release year) than voles released later (odds ratio $=0.804, \mathrm{P}<0.001$ ) and persisted in the study population for longer (Spearman's $\rho=-0.397, P<0.001$, for week of release and days between release and final capture < early summer the following year) (Mathews et al. 2006). Although intraspecific competition between release cohorts in this study is likely, there are additional concerns that releasing water voles into vacant habitat in autumn will not allow sufficient time for individuals to secure an overwinter range with adequate resources in order to survive. Furthermore, because previous research showed mean vegetation abundance to inversely correlate with dispersal distance of voles reintroduced in spring $(n=155, \beta=-0.026)$ (Moorhouse et al. 2009), individuals may be forced to undertake longer exploratory movements in response to autumn dieback of vegetation, placing them at increased risk of predation (Dean et al. 2016). Current guidance sets out to allay these risks; however, supporting research into the postrelease movements and survivorship of water voles translocated in autumn is currently lacking. Given the high financial costs of housing individuals in captivity, alongside additional health and welfare risks that may be associated with a captive environment (Mathews et al. 2006; Morgan and Tromborg 2007; Gelling et al. 2015; Hartley and Sainsbury 2017), it is important that mitigation guidance is supported by empirical evidence.

This paper aims to verify overwinter survival and post-release movement of water voles translocated in autumn to provide an evidence base for current translocation guidance. We use radio tracking and mark recapture data from translocated and resident populations that were collected during a live development project to analyse the post-release movements and overwinter survival of water voles 
translocated in autumn for mitigation purposes. We compared weekly movement data to investigate settlement and calculated dispersal distances and final locations to identify how widely translocated water voles searched the release area for habitat in which to settle. These metrics are important considerations when assessing success and provide valuable information to inform on future translocations. Based on previous studies, we predicted that (a) translocated water voles would have a lower overwinter survival than the resident population; (b) the distances moved by translocated voles would be larger than those by resident individuals and those previously reported for water voles released in spring.

\section{Methods}

\section{Study area}

The study was carried out on three sites located within the London Gateway Port (DP World) scheme boundary located next to the village of Corringham, Essex, between the coordinates 50.50 to $51.51^{\circ} \mathrm{N}$ and 0.43 to $0.49^{\circ} \mathrm{W}$ (Fig. 1). The three sites included the Logistics Park (LP), a construction site which supported a population of water voles to be translocated; the Western Grazing Marsh (WGM), which was not occupied by water voles but would act as a receptor site for the translocated population from LP; and the Stanford Boundary Drain (SBD) which supported a resident population that would be unaffected by the scheme and which were used as a control. The absence of water voles from the WGM receptor site was confirmed by extensive field sign surveys in spring and autumn 2015 and reconfirmed before translocation. Although optimal in habitat at the time of release, previous poor management had resulted in the extensive loss of vegetation cover and presumed loss of the population. The WGM and SBD sites were separated by $200 \mathrm{~m}$ of unsuitable habitat (road and carpark) and located $2 \mathrm{~km}$ and $850 \mathrm{~m}$ from site LP, respectively. Both WGM and SBD formed part of an extensive, lowland grazing marsh habitat which was dissected by well-connected reed-lined ditches of permanent water which had no evidence of mink and which were under an ongoing mink control programme.

\section{Live capture and translocation}

This study was conducted in parallel with an active development project and therefore was constrained in study design and by conditions stipulated under Natural England licence (2016-22064-SCI-SCI). Live capture and translocation followed best practice guidelines (Strachan et al. 2011; Dean et al. 2016).

Live capture of water voles was carried out between 17 September and 15 October, 2015, at sites LP and SBD. At both sites, Greenatyle ${ }^{\mathrm{TM}}$ water vole live capture traps (Wildcare) were provided with bedding and bait (carrot and apple) and 
placed on floating rafts at 15-m intervals along the length of channels (trapping areas are shown in Fig. 1) where burrows, feeding signs and latrines indicated water vole presence. The locations of each trap were recorded using a Garmin ETrex Summit GPS receiver (Garmin Ltd., Romsey, Hants; maximum recording error of $10 \mathrm{~m}$ ). Traps were checked three times per day and biometric data (sex, weight (g) and breeding condition) were recorded for each newly captured individual. Fifteen individuals from the SBD control site and 15 individuals from the LP construction site that weighed > $180 \mathrm{~g}$ were fitted with VHF radio collars (Pip Ag 393 cable tie with whip antenna collars, Biotrack Ltd., Dorset, UK). The expected battery life of the collars is a maximum 16 weeks, with an effective battery life of 12 weeks. In addition to collaring, nine collared individuals and a further 18 non-collared individuals were also permanently marked using Trovan ${ }^{\circledR} 2 \mathrm{~mm} \times 32 \mathrm{~mm}$ PIT tag (ID-162B/1.4). Traps were set for a total of 13 nights at site SBD and all individuals were re-released at their point of capture. For site LP, traps were set for between 8 and 18 nights and all individuals were translocated from the construction site on the day of their capture and released into soft release pens at site WGM. A summary of the trapping effort and study design is given in Table 1. Trapping ceased once five consecutive days with no captures had been achieved and no field signs of water voles were observed. After which, all suitable habitats were removed, and a search of burrows was carried out to ensure that all voles had been removed (as stipulated under licence and in line with guidance (Dean et al. 2016)).

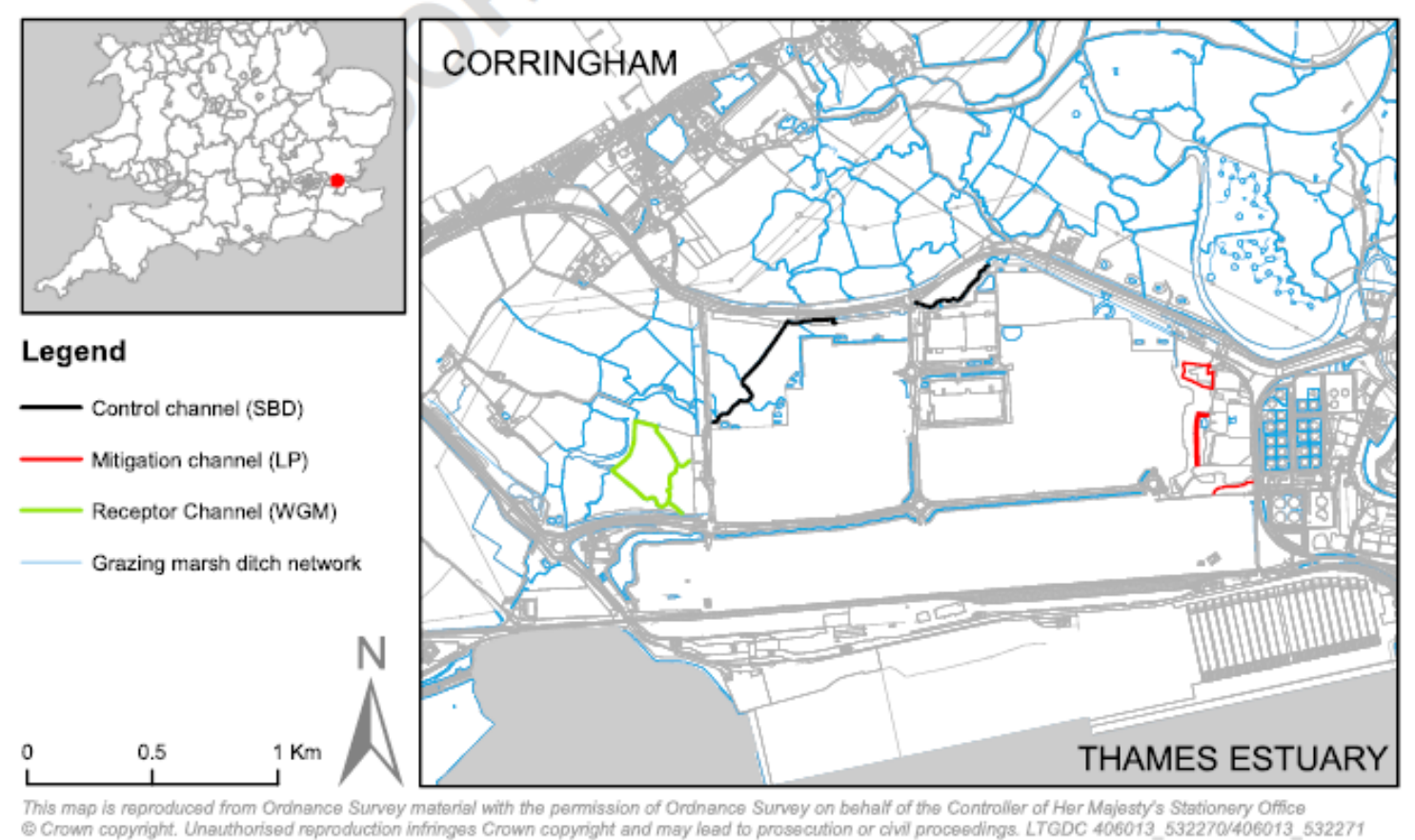

Fig. 1 Map showing the location of water vole populations that were trapped in autumn 2015 and spring 2016 and adjoining grazing marsh ditch network within the London Gateway Port development, Thames Estuary, UK

Recapture of collared and marked individuals was carried out between 15 and 21 March, 2016, to establish overwinter survival and to remove collars. Traps were 
placed on floating rafts at 15-20-m intervals along the length of the WGM receptor channel and the SBD control channel. Traps were set for six consecutive days which was twice the length of time taken to capture $80 \%$ of individuals on the control channel in autumn. Trapping was not conducted between 1 November and 1 March due to licence conditions and limitations of effective trappability of voles that remain sedentary in their burrows during winter (Carter and Bright 2003; Dean et al. 2016). Traps were not set outside of the two study channels to retrieve collars from animals that may have dispersed as the batteries of collars had expired and trapping an extensive (39 ha) area of ditch networks was not feasible.

\section{Soft release protocol}

Soft release of voles followed best practice guidance as detailed in Strachan et al. (2011). In brief, this consisted of placing galvanised pyramid soft release pens at 50$\mathrm{m}$ intervals along the banks of site WGM. Each pen measuring $0.5 \mathrm{~m} \times 0.5 \mathrm{~m}$ was partially dug into the ground and provided with bedding and food (carrot and apple). Each pen housed a single individual and males and females were released into alternate pens to reduce competition between same-sex individuals. To reduce immediate competition with translocated adults for new territories and food resources, young juveniles weighing $<100 \mathrm{~g}$ were released into one area of the same receptor site alongside females associated with the litters, but not alongside other adults. The locations of each pen were recorded using a Garmin ETrex Summit GPS. The soft release pens were left in place for 7 consecutive days, and all individuals had burrowed out of the pens within 2 days.

\section{Radiotracking}

Radio-collared animals were located once per week, for a period of 10 weeks using radiotelemetry. On each sampling occasion, systematic searches of all suitable habitat within $2 \mathrm{~km}$ (the normal dispersal range for water voles) of the study sites were carried out during daylight hours. The expected detection ranges of collars were $\sim 500 \mathrm{~m}$ for active animals (outside of burrows); however, this was reduced to $\sim 5 \mathrm{~m}$ for water voles that were in burrows. We were unable to obtain the positions of all individuals for each of the monitoring weeks due to intermittent signals obtained from some collars. In total, $15 \%$ of all possible detections $(N=300)$ were classified as false negatives, where failure to detect was followed by a detection during subsequent sampling weeks. All locations were recorded using a Garmin ETrex Summit GPS and were mapped using geographic information system ARCVIEW GIS v10.2 (Environmental Systems Research Institute, Inc., Redlands, CA, USA). 


\begin{tabular}{|c|c|c|c|c|c|c|}
\hline \multirow[t]{2}{*}{ Study site } & \multirow{2}{*}{$\begin{array}{l}\text { Length } \\
\text { trapped bank }\end{array}$} & \multicolumn{4}{|c|}{ Autumn 2015} & \multirow{2}{*}{$\begin{array}{l}\text { Spring } 2016 \\
\text { No. of trap } \\
\text { nights }\end{array}$} \\
\hline & & $\begin{array}{l}\text { No. of trap } \\
\text { nights }\end{array}$ & $\begin{array}{l}\text { No. of } \\
\text { voles PT }\end{array}$ & $\begin{array}{l}\text { No. of } \\
\text { voles RC }\end{array}$ & $\begin{array}{l}\text { No. of voles marked } \\
\text { and released }\end{array}$ & \\
\hline LP (translocated) & 1100 & 860 & $5 \mathrm{M}: 5 \mathrm{~F}$ & $8 \mathrm{M}: 7 \mathrm{~F}$ & 0 & - \\
\hline SBD (control) & 1100 & 520 & $10 \mathrm{M}: 7 \mathrm{~F}$ & $11 \mathrm{M}: 4 \mathrm{~F}$ & $14 \mathrm{M}: 10 \mathrm{~F}$ & 240 \\
\hline WGM (receptor) & 1100 & - & - & - & $12 \mathrm{M}: 12 \mathrm{~F}$ & 264 \\
\hline Total & 3300 & 1380 & 27 & 30 & 48 & 504 \\
\hline
\end{tabular}

\section{Statistical analysis}

\section{Apparent survival and weight changes}

Recapture of resident and translocated individuals in spring was used as a measure of overwinter apparent survival and did not account for animals that had dispersed from their respective populations. The probability of recapture was analysed using binary logistic regression, with Firth's correction for rare events (to account for complete or quasi-separation of explanatory variables in relation to a low recapture rate) (Firth 1993). Treatment type (translocated vs resident), gender (male vs female), marking method (PIT-tagged, radio-collared, radio collared and PITtagged) and the pre-overwinter weight ( $\mathrm{g}$ ) of individuals were included as explanatory variables. Only main effects were included in the analysis and nonsignificant terms were removed using backwards selection to provide minimum adequate models of significant effects. Weight was centred at the mean, prior to analysis to allow for meaningful interpretation of coefficients (Aiken and West 1991). Insufficient sample sizes and constraints on study design prevented the use of more robust capture-recapture models, which account for capture probabilities and emigration, to estimate survival. A Wilcoxon signed-rank test was used to investigate changes in weight between autumn and spring for recaptured individuals.

\section{Post-release movements}

Distances moved by resident and translocated individuals were restricted to follow ditch lines, following the same methodology of previous monitoring of water voles released in spring (Moorhouse et al. 2008). Although water voles will also disperse overland (Telfer et al. 2001; Telfer et al. 2003; Q3 Fisher et al. 2009), we considered this less likely given the low vegetation cover that was present within the intervening habitat matrix (improved grassland and tilled land).

Weekly activity patterns were examined using the distances between weekly location fixes for translocated and resident individuals. For each monitoring week, only individuals whose location was known for the preceding week were included. 
We examined the mean weekly distances (MnWD) of translocated and resident individuals. MnWD of the translocated individuals was used to determine whether movement decreased over time as an indication of post-release settlement. Because of small and unbalanced samples across individuals, we did not statistically test the influence of time on weekly distance moved. The maximum weekly distance (MWD) moved by individuals during the monitoring period was compared between treatments (translocated vs resident) and gender using analysis of variance (ANOVA). Analysis included the MWD for those individuals with more than one relocation fix $(n=25)$ as MWD did not correlate with the number of times an animal was located (Spearman's rho $=3280.119, \mathrm{~S}=2290.3, \mathrm{P}=0.57$ ). MWD was log transformed for 329 analysis to meet the assumptions of the test.

\section{Dispersal and release site fidelity}

Dispersal distance (DD) was taken as the longest distance moved along ditch lines by translocated individuals from their release location within the 10-week monitoring period and was used to assess how widely released individuals searched for habitat in which to settle. Differences between male and female DD were tested using Welch's $t$ test. All individuals with more than one relocation fix were included in the analysis as the number of relocation points did not correlate with DD (Pearson's r11 $=-0.01, n=13, P=0.96$ ). The distance, following ditch lines, between release locations and the final location (start-end $D$ ) was calculated and used to assess the degree of release site fidelity. Start-end $D$ were only calculated for individuals whose last location was obtained after 5 weeks of monitoring $(n=11)$ as preliminary data analysis showed this to be the earliest point at which translocated voles began to settle. Gender differences in start-end D were investigated using Welch's t test.

All analyses were conducted in R Version 3.3.1 (www.rproject.org, accessed 21 June 2016). Results were considered significant if $P<0.05$ and are presented as mean + standard error.

\section{Results}

\section{Overview of capture data}

A total of 48 individuals were captured and marked across the two treatment groups in autumn 2015 (Table 1). In spring 2016, 19 and 21 individuals were captured on the control and receptor channel, respectively, of which $16.7 \%$ were recaptures of individuals marked solely using PIT tags the previous autumn. Of these, $75 \%$ were from the translocated population and $75 \%$ were female. A summary of recapture rates by each predictor variable relating to overwinter survival is 362 provided in Table 2. 
Table 2 Distribution of each predictor variable with the outcome in spring recapture data of water voles

\begin{tabular}{|c|c|c|c|c|c|}
\hline \multirow[t]{3}{*}{ Variable } & \multirow{3}{*}{$\begin{array}{l}N \\
48\end{array}$} & \multicolumn{4}{|c|}{ Recaptured } \\
\hline & & \multicolumn{2}{|c|}{ Yes $(\%)$} & \multicolumn{2}{|c|}{ No $(\%)$} \\
\hline & & 8 & $16.7 \%$ & 40 & $83.3 \%$ \\
\hline \multicolumn{6}{|l|}{ Treatment type } \\
\hline Translocated & 24 & 6 & $75.0 \%$ & 18 & $45.0 \%$ \\
\hline Control & 24 & 2 & $25.0 \%$ & 22 & $55.0 \%$ \\
\hline \multicolumn{6}{|l|}{ Sex } \\
\hline Male & 26 & 2 & $25.0 \%$ & 24 & $60.0 \%$ \\
\hline Female & 22 & 6 & $75.0 \%$ & 16 & $40.0 \%$ \\
\hline \multicolumn{6}{|l|}{ Marking method } \\
\hline PIT-tagging & 18 & 8 & $100.0 \%$ & 10 & $25.0 \%$ \\
\hline PIT-tagging and radio-collaring & 9 & 0 & $0.0 \%$ & 9 & $22.5 \%$ \\
\hline Radio-collaring & 21 & 0 & $0.0 \%$ & 21 & $52.5 \%$ \\
\hline Weight (g): mean (SD) & 48 & 142.5 & $(42.1)$ & 189.7 & $(28.1)$ \\
\hline
\end{tabular}

\section{Apparent survival}

The results of binomial regression analysis showed that "marking type" was the only significant factor affecting apparent overwinter survival and revealed that the odds of recapturing radio-collared voles was lower (radio-collared $\mathrm{OR}=0.03, \mathrm{Cl}=0-0.27$, radio-collared and PIT-tagged $\mathrm{OR}=0.07, \mathrm{Cl}=0-0.65)$ than the odds of recapturing PIT-tagged voles $(\mathrm{OR}=0.8, \mathrm{Cl}=0.31-2)($ Table 3$)$. Treatment did not have a significant effect on the probability of recapture $\left(X^{2} 1=2.79, N=48, P=0.09\right)$, indicating translocated voles were as likely to have survived to be recaptured in spring as residents. Due to the complete separation of radio-collared individuals in the data (i.e. no radio-collared individuals were recaptured), the same modelling procedure was carried out excluding marking type as a main effect. The final model included weight as the only significant variable $\left(\beta=-0.04, \mathrm{SE}=0.01, \mathrm{X}^{2} 1=10.40\right.$, $N=48, P=0.001$ ) indicating that increasing weight reduced the probability that individuals survived to be recaptured in spring $(\mathrm{OR}=0.97, \mathrm{Cl}=0.93-0.98)$. A Chisquared test on the difference in penalised likelihood ratio (PLR) between the two models was not significant (Modelmark PLR $=14.17$, Modelwgt PLR $=10.40, X^{21}$ $=8.399, \mathrm{P}=0.052$ ). 
Weight changes of water voles recaptured in spring are shown in Fig. 2 . Of the 8 water voles recaptured in spring, one individual lost $10 \mathrm{~g}$ in weight overwinter, 3 individuals weighing between $150 \mathrm{~g}$ and $180 \mathrm{~g}$ maintained the same weight and the remaining 4 individuals gained between $10 \mathrm{~g}$ and $70 \mathrm{~g}$ with the largest increase observed in a juvenile weighing $50 \mathrm{~g}$ in autumn. A Wilcoxon signed-rank test indicated that these weight changes were not significant $(Z=1.5, P=0.14)$; however, due to the sample size this test has low statistical power.

\section{Overview of radiolocation data}

Including initial release (translocated) and capture (resident) locations, a total of radiotelemetry locations were obtained for the translocated $(n=102)$ and resident $(n=107)$ water voles. The mean (+SE) number of radiolocations obtained for individuals was $5.5(+0.7)$ for the translocation group and $6.64(+0.7)$ for residents. One female from the translocated group and one resident male were not relocated following initial tagging. Of the remaining 28 individuals, 82\% (23) were relocated in week one and by the end of the study, 32\% (9) individuals had been relocated, of which 4 were from the translocated group and 5 were residents. Two neighbouring males from the resident colony dispersed over $1.3 \mathrm{~km}$ between weeks 8 and 9 and did not return to the control site. Prior to this, their mean weekly movements were $25+7 \mathrm{~m}$ and $14+9 \mathrm{~m}$, which are consistent with other resident males' (Table 4), and thus their movements prior to dispersal were included in the analysis.

\section{Post-release movements}

A total of 150 weekly distances were calculated for the translocated $(n=66)$ and resident $(n=84)$ water voles. The mean $(+S E)$ number of weekly distances was 5.5 $(+1.6)$ and $6.2(+1)$ for resident females and males, respectively, and $3.2(+1.3)$ and 5.8 (+1.2) for translocated females and males, respectively. MnWD of residents remained relatively constant across the monitoring period for males (range 11-80 $\mathrm{m}$ ) and for females (range 0-37 m), whilst translocated voles varied from 23 to 227 mformales and 8 to $212 \mathrm{~m}$ for females (Fig. $3 a$ and b). The MnWD of translocated voles did not show a pattern of stabilisation over time. For males, the MnWD declined over the first 5 weeks of monitoring and increased again from week 8, owing to longer distances travelled by two males (TV06 and TV12). From the location data (Fig. 4a), 5 males had re-occurring locations around their last known location, suggesting they may have located an area in which to settle. 
Table 3 Results of logistic regression analysis showing minimum adequate model of significant effects on the probability of recapture in spring. Values of the model are likelihood ratio test $=14.167_{2,48}, P=<0.001$

\begin{tabular}{lccccc}
\hline Variable & df & beta & SE & $P$ value & OR \\
\hline Intercept & & -0214 & 0.474 & 0.646 & 0.810 \\
Marking method & & & & & $0.318,2.001$ \\
$\quad$ PIT-tagged and radio-collared & 1 & -2.733 & 1.601 & 0.016 & 0.065 \\
$\quad$ Radio-collared & 1 & -3.550 & 1.539 & 0.000 & 0.029 \\
\hline
\end{tabular}

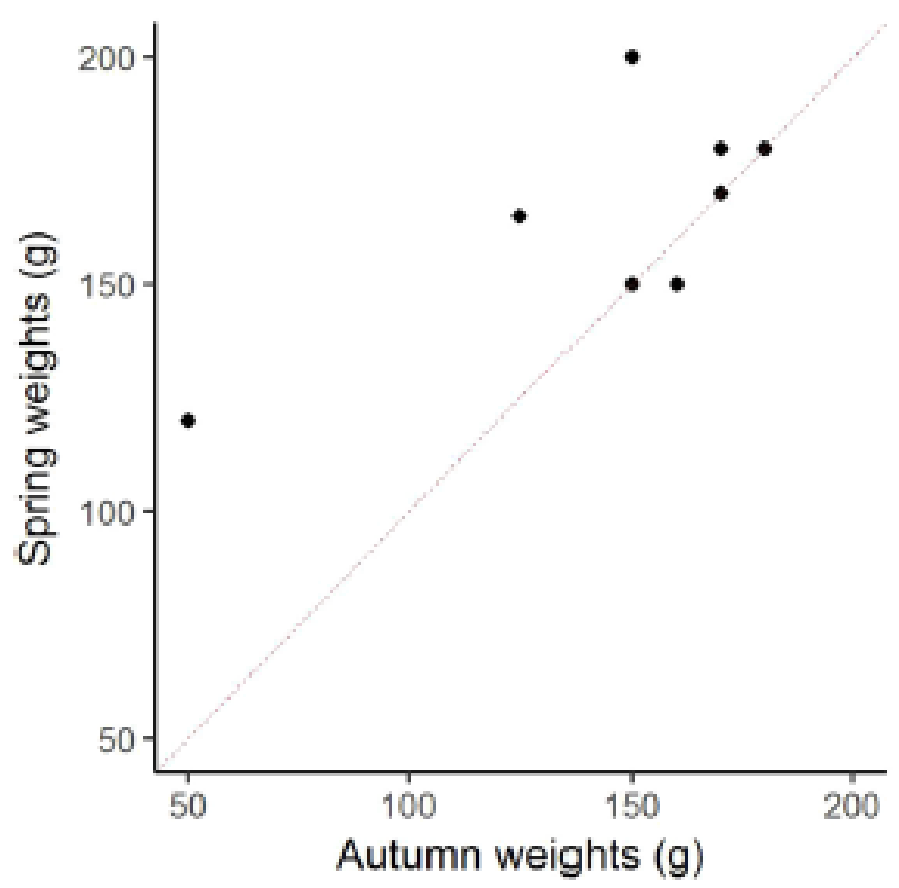

Fig. 2 Scatter plot showing autumn and spring weights (g) of recaptured water voles. Reference line shows $y=x$ with the null expectation that weight does not change over time

The MnWD of translocated females showed a repeated cycle of large movements followed by short periods of activity in a small area. By the end of the study period, there was insufficient evidence that any of the collared females had settled (Fig. 4b). The MWD for the translocated group was $936 \mathrm{~m}$ for male TWV06 and $415 \mathrm{~m}$ for female TWV07. Both these movements occurred during the latter half of the monitoring period (weeks 8-9 for TWV06 and weeks 6-7 for TWV07). The MWD moved by a resident male and female was $315 \mathrm{~m}$ and $69 \mathrm{~m}$, respectively. Results of the analysis of variance showed "treatment" (translocated vs control) to significantly affect MWD with translocated individuals moving significantly further than resident animals $(F 1,21=51.9, P<0.001)$ (Fig. 5). There were no significant gender differences in MWD for either treatment group, as shown by a non-significant interaction between sex and treatment $(\mathrm{F} 1,21=0.45, \mathrm{P}<0.511)$. 
Post-release DD of 13 (7 M:6 F) translocated water voles ranged from 145 to 846 $\mathrm{m}$. Of the translocated males, individual TWV08 moved the furthest distance (846 $\mathrm{m}$ ) between the first and second weeks following release. The furthest DD for females was undertaken by individual TWV07 who moved a similar distance away from her release location (TWV07: $843 \mathrm{~m}$ ) but did so after 7 weeks following release. Mean DD was similar for males $(473 \mathrm{~m}+229 \mathrm{~m})$ and females $(503 \mathrm{~m}+240 \mathrm{~m})$ (t10.5 $=-0.22, P=0.83)$. The last known locations of individuals $(n=11)$ were all within $800 \mathrm{~m}$, along ditch lines. Start-end D ranged from 145 to $465 \mathrm{~m}$ (mean $=348 \mathrm{~m}$ ) for males $(n=6)$ and from 89 to $777 \mathrm{~m}$ (mean $=430 \mathrm{~m})$ for females $(n=5)$, and was not significantly different between genders ( $\mathrm{t} 5=0.57, \mathrm{P}=0.59)$. When compared to the maximum dispersal distances for these same individuals, $63 \%$ of individuals had moved closer to their release sites by the end of the study and $67 \%$ of all individuals remained on the receptor channel.

\begin{tabular}{|c|c|c|c|c|c|c|c|}
\hline Treatment & Individual ID & Sex & $\mathrm{N}$ & Mean & Min & $\operatorname{Max}$ & SE \\
\hline \multirow[t]{16}{*}{ Control } & CWV19 & $\mathrm{F}$ & 1 & 17 & 17 & 17 & 0 \\
\hline & CWV20 & $\mathrm{F}$ & 6 & 6 & 0 & 19.6 & 2.9 \\
\hline & CWV24 & $\mathrm{F}$ & 7 & 11.3 & 2.0 & 46.4 & 5.9 \\
\hline & CWV30 & $\mathrm{F}$ & 8 & 25.3 & 2.2 & 69.4 & 9.51 \\
\hline & OVERALL & $F$ & 22 & 15.2 & 0 & 69.4 & 9.9 \\
\hline & CWV15 & M & 10 & 25.4 & 0 & $61.1 * 1342.6$ & 7.02 \\
\hline & CWV16 & M & 8 & 14.2 & 0 & $65.2 * 1465.3$ & 8.66 \\
\hline & CWV18 & M & 5 & 6.1 & 2.6 & 11.7 & 1.52 \\
\hline & CWV22 & M & 10 & 7.5 & 1 & 21.4 & 2.02 \\
\hline & CWV23 & M & 10 & 98.7 & 2.8 & 314.7 & 30.77 \\
\hline & CWV25 & M & 3 & 9.8 & 5.7 & 12 & 2.08 \\
\hline & CWV26 & M & 7 & 5.8 & 2.2 & 14.3 & 1.55 \\
\hline & CWV27 & M & 3 & 17.8 & 10.8 & 23 & 3.64 \\
\hline & CWV28 & M & 2 & 17.2 & 5.1 & 29.2 & 12.3 \\
\hline & CWV29 & M & 4 & 25.2 & 17.1 & 31.2 & 3.45 \\
\hline & OVERALL & $M$ & 84 & 28.9 & I & $314.7 * 1465.3$ & 16.32 \\
\hline \multirow[t]{16}{*}{ Translocated } & TWV03 & $\mathrm{F}$ & 4 & 61.2 & 14.3 & 130.5 & 26.85 \\
\hline & TWV05 & $\mathrm{F}$ & 3 & 62.4 & 62.4 & 62.4 & 0 \\
\hline & TWV07 & $\mathrm{F}$ & 5 & 146.8 & 7.9 & 414.5 & 73.7 \\
\hline & TWV09 & F & 3 & 179.9 & 9.5 & 281.3 & 85.68 \\
\hline & TWV11 & F & 1 & 342.7 & 342.7 & 342.7 & 0 \\
\hline & TWV13 & $\mathrm{F}$ & 5 & 93.6 & 6 & 398.6 & 34.3 \\
\hline & OVERALL & $F$ & 21 & 135.6 & 6 & 398.6 & 21.23 \\
\hline & TWV02 & M & 8 & 74.9 & 9.8 & 207.2 & 27.72 \\
\hline & TWV04 & M & 4 & 132.4 & 11.2 & 251.3 & 49 \\
\hline & TWV06 & M & 7 & 369.6 & 5.5 & 935.8 & 147.6 \\
\hline & TWV08 & M & 2 & 423.7 & 205.4 & 641.9 & 218.28 \\
\hline & TWV 10 & M & 1 & 173 & 173 & 173 & 0 \\
\hline & TWV12 & M & 7 & 153.8 & 8.5 & 465.2 & 66.6 \\
\hline & TWV14 & M & 10 & 66.2 & 1.5 & 481.5 & 46.33 \\
\hline & TWV17 & M & 7 & 45.5 & 3.6 & 147.5 & 21.43 \\
\hline & OVERALL & $M$ & 46 & 147.8 & 1.5 & 935.8 & 82.87 \\
\hline
\end{tabular}

Table 4 Weekly distance $(\mathrm{m})$ parameters for control (outlined boxes) and translocated (shaded boxes) water voles, where $\mathrm{N}$ shows total number of fixes and data in italics show distance parameters by gender and treatment group 


\section{Discussion}

\section{Apparent overwinter survival of translocated and resident water voles}

Current mitigation guidance for water voles in the lowland England suggests that translocation during autumn should only be carried out as a "last resort", as individuals are likely to be at higher risk of overwinter mortality (Dean et al. 2016). Whilst this guidance is based on the best available biological knowledge of the species and available accounts of previous relocation/reintroduction attempts (Mathews et al. 2006; Moorhouse et al. 2009; Strachan et al. 2011; Gow et al. 477 2012), there has been no empirical evidence to support this recommendation. Our recapture data, although based on a small number of individuals, suggests that water voles released into suitable habitat in autumn did not exhibit lower apparent overwinter survival than residents. In fact, the spring recaptures of translocated voles exceeded those of the resident population, where just 2 of the 24 marked individuals were reencountered (Table 2). The high turnover of individuals in both populations is typical for water voles, a species that conforms to a metapopulation system in which high mortality rates and dispersal are regularly observed (Telfer et al. 2003; Aars et al. 2006). Although we found no evidence that our collared females had settled on the receptor site by the end of December, 5 of the 6 translocated voles that were reencountered in spring were uncollared females. This indicates that at least $40 \%$ of the females released survived and settled within the receptor channel. Only a single uncollared male in each treatment group was re-encountered. Whilst gender was not a significant factor influencing the probability of recapture in this study, significantly lower recapture rates of males released in spring were reported by Moorhouse et al. (2009). The authors proposed that the larger postrelease movements of males may have placed them at increased risk of predation; this, however, was not observed in our study as males moved similar distances from their release locations as females.

Although water vole mortality overwinter can be as high as 70\% (Carter and Bright 2003; Strachan et al. 2011), the apparent survival of $25 \%$ and $8 \%$ of translocated and resident individuals in the study is likely to be underestimated as failure to re-encounter individuals from both treatment groups, did not necessarily mean that they died. Dispersal is common in spring and autumn in water voles (Stoddart 1970) and based on our movement data, at least 8 collared individuals (5 translocated and 3 resident) had left their respective populations by the end of the radiotracking period in December (Fig. 4a-d). Dispersal was also evidenced by the number of new individuals that had entered both populations by spring (WGM Receptor channel $=15$, SBD Control channel $=17$ ). We are unable, however, to distinguish between survival and dispersal from our data owing to the small sample size and constraints on study design. 

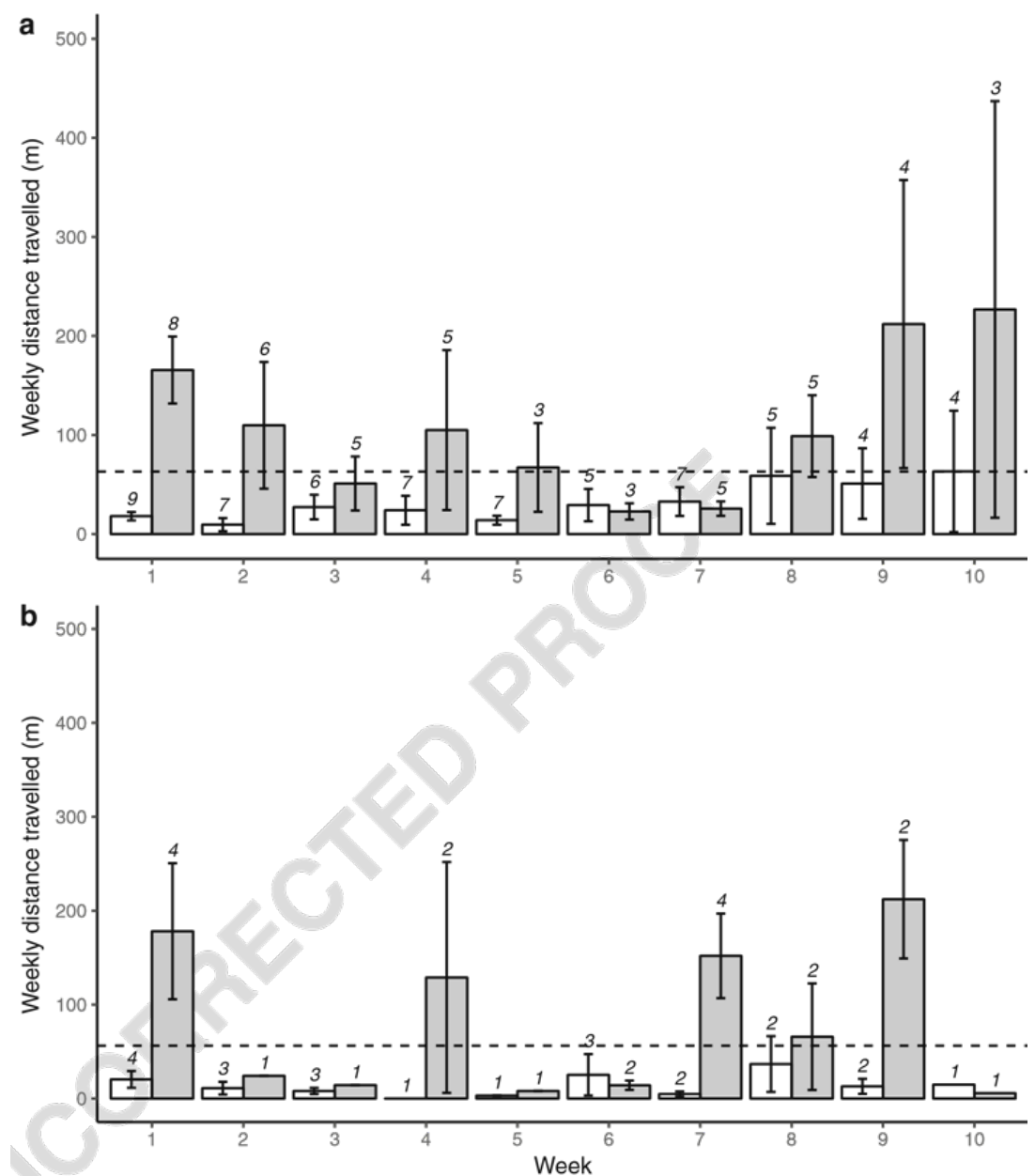

Fig. 3 Bar chart showing mean weekly distances $(\mathrm{m})$ moved by resident (outlined bars) and translocated (grey bars) male (a) and female (b) water voles. Distances used are for individuals whose location in the preceding week was known. Error bars represent standard error; numbers below bars represent sample sizes used to calculate mean distances. The hashed horizontal line represents 1.5 times the upper 95\% confidence interval of weekly mean distance travelled by residents over the 10 monitoring weeks and is used a reference for settlement of translocated individuals

Both radio-collaring and increased weight were found to significantly reduce the probability of capturing marked individuals the following spring. These are not mutually exclusive, given that voles weighing $>180 \mathrm{~g}$ in autumn were fitted with radio collars. Whilst off-site dispersal is likely to have contributed, none of the 30 collared voles in our study were recaptured the following spring. Age-related mortality may be one causative factor, given that we only collared adult water voles and these rarely survive more than two winters (Strachan et al. 2011). The duration that voles carried their collars may also have had a negative impact on their survival. Radio-collaring during summer has previously been found to reduce the condition of breeding female water voles resulting in male-biased offspring (Moorhouse and Macdonald 2005). Further, collaring is also reported to reduce movement (Banks et al. 1975), digging ability (Corner and Pearson 1972) and overwinter survival (Webster and Brooks 1980) 
in other small mammals. We, however, consider this to be unlikely as previous research on water voles radio-collared for a similar amount of time overwinter did not report any adverse effects of collaring on survival (Carter and Bright 2003). In fact, they found that of the $54 \%$ of individuals $(\mathrm{N}=61)$ that died, predation accounted for $94 \%$. Whilst we found no field evidence that the collared voles were predated (no corpses or collars with signs of predation) before the collar batteries expired, the study by Carter and Bright typically found corpses of voles in their burrows. These were mainly ascribed to predation from mustelids (mink, stoat Mustela erminea and weasel M. nivalis); and whilst American mink were not present in our study area, predation by other mustelids is likely to have occurred between capture sessions.

Of the surviving voles, all 8 were classified as young of the year the previous autumn and weighed $<180 \mathrm{~g}$. These included 6 of the 7 translocated juveniles that were recaptured on the receptor channel in spring. As this age class will produce most of the following year's litters (Leuze 1976; Telfer et al. 2003), the overwinter survival and persistence of these individuals on the receptor channel is noteworthy. Previous accounts state that individuals need to attain a weight of $\sim 170 \mathrm{~g}$ to increase their winter survival (Strachan et al. 2011); however, only 3 individuals weighed this or above. In fact, one translocated vole weighing $50 \mathrm{~g}$ in autumn successfully overwintered and had gained $70 \mathrm{~g}$ in weight by spring (Fig. 2). Although our observations are based on a small number of individuals, one possible factor for their persistence on the receptor site is that all translocated juveniles were released into a separate area of the receptor site from other adults. Other studies have shown that dispersal by juveniles is driven by competition with adult for resources (Leuze 1976) and that dispersers are more likely to settle in low- rather than high-density populations (Fisher et al. 2008). Releasing juveniles away from competing adults may therefore have facilitated their settlement and survival on the receptor site, both of which are important when considering translocation success.

\section{Post-release movements, settlement and release site fidelity}

Our movement data concurs with our predictions that distances moved by translocated voles would be larger than residents' and those previously reported for water voles released in spring. We found the maximum weekly distances moved by our translocated voles were significantly larger than those of the control group of residents. This is consistent with the expectation that individuals released into a novel environment will undertake larger exploratory movements to allow them to gain knowledge in order to survive (Berger-Tal and Saltz 2014). We found that both males and females explored the release area to a similar extent (mean DD of males $743 \mathrm{~m}$, of females $503 \mathrm{~m}$ ) and that these distances were 3.5 and 5 times the length of mean maximum distances dispersed by radiotracked captive-bred voles released in spring ( mean $=588137 \mathrm{~m}$, range $=32-344 \mathrm{~m}$; Moorhouse et al. 2009). Moorhouse et al. 
(2009) also found that female dispersal was half that of males, which was not observed in our study. As water vole movement has been found to decrease with increasing vegetation abundance (Moorhouse et al. 2009), it is plausible that autumn die-back of vegetation was a contributing factor for the longer, and arguably more risky, movements made by both males and females. However, our data is in line with that of previous studies that found dispersal is frequent in both sexes (Telfer et al. 2003; Aars et al. 2006). Further, the dispersal distances we observed were well within the mean dispersal range for water voles $(1.8 \mathrm{~km})$ (Telfer et al. 2003). Therefore, the distances we observed voles travelling following their release in autumn may not be a limiting factor for a species that conforms to a metapopulation system where dispersal in both spring and autumn is frequent.

a)

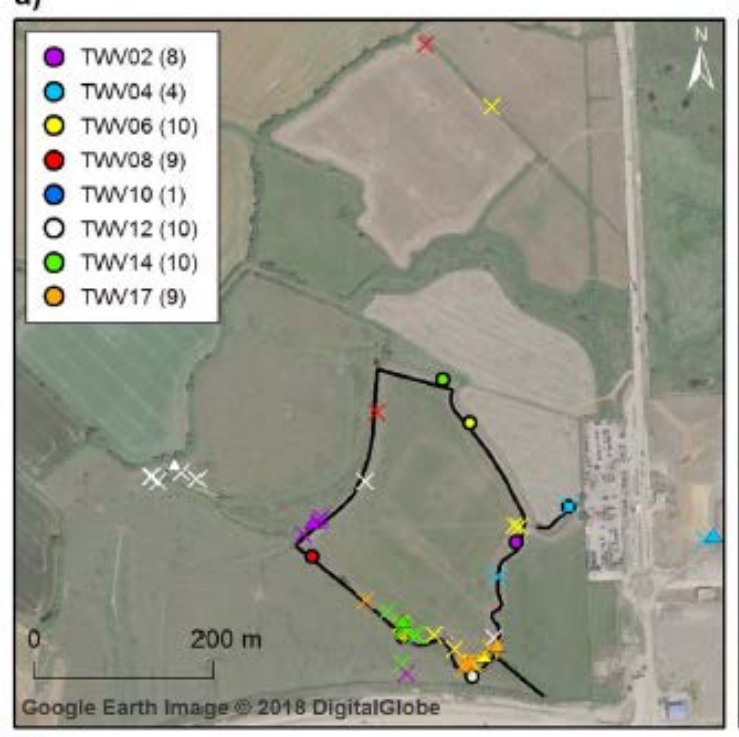

c)

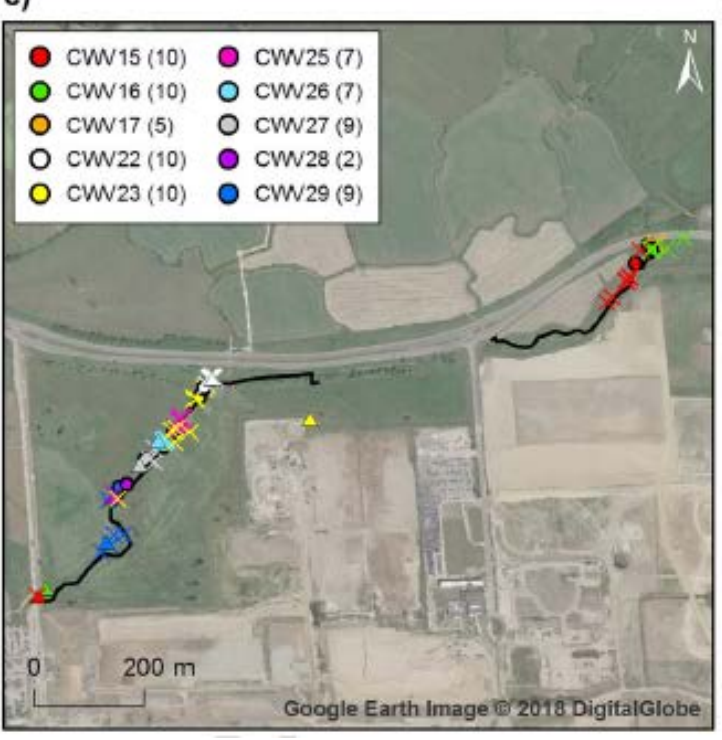

b)

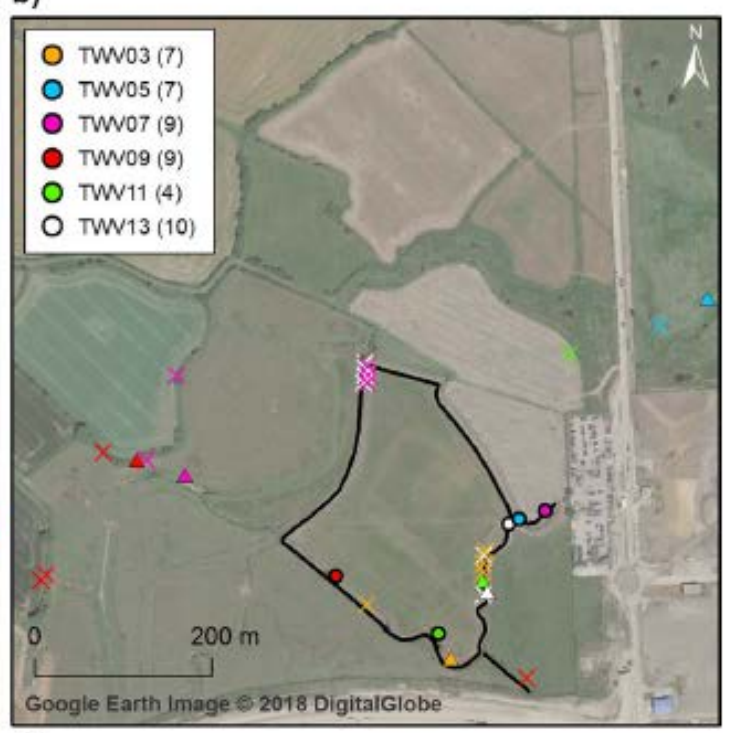

d)

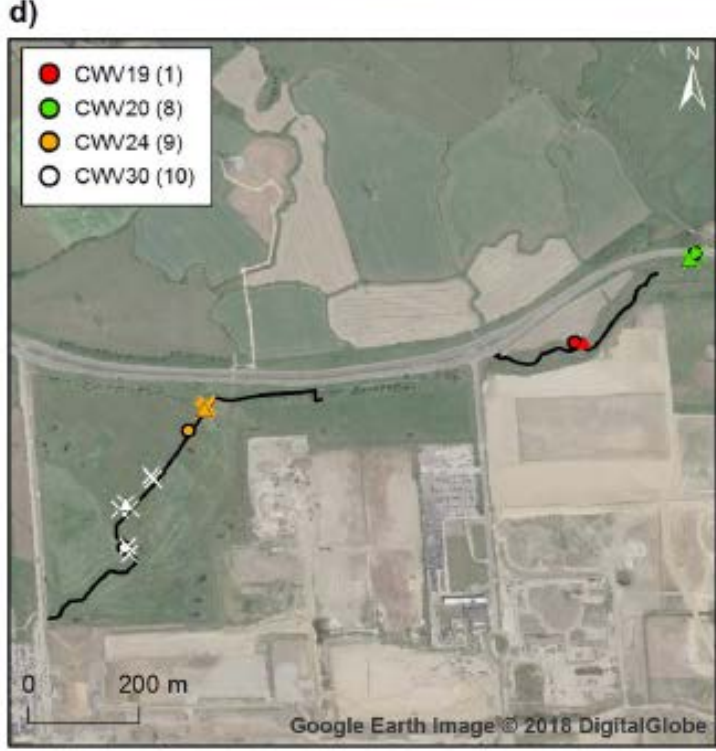

Fig. 4 Movement patterns of translocated male (a) and female (b) and resident male (c) and female (d) water voles, where colours define individuals, circles show release location, diamonds show last known location and crosses show intermediate locations. Black lines show area trapped in autumn 2015 and spring 2016. Legend shows individuals' identification number and last known location week in parentheses 


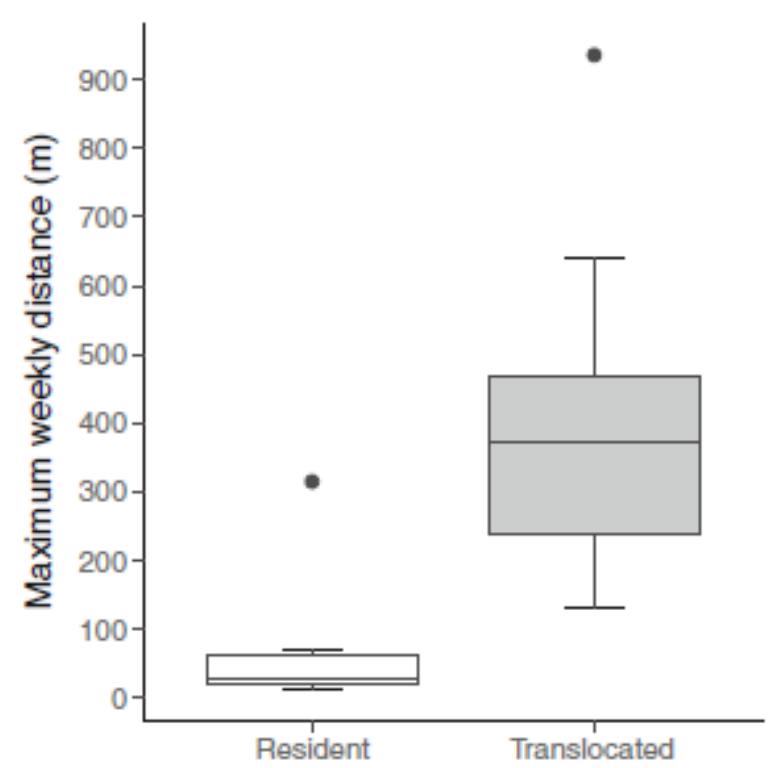

Fig. 5 Boxplot diagram showing maximum weekly distances (MWD) of translocated $(n=12$, median $=370.7$, range $=130.5-935.8)$ and resident $(n=13$, median $=29.3$, range $=11.7-314.7)$ water voles

We found no evidence from our MnWD data that either sex settled within the 10week period. The location data for males (Fig. 4a), however, suggested that 5 of the 8 males were last known to be in areas they had been located at during previous monitoring weeks. This suggests that these males had located favourable areas in which to settle, of which only one was located outside the receptor channel. We did not, however, recapture any of these males in spring, thus settlement cannot be confirmed. In comparison, females showed erratic movement, dispersing to temporary patches for a week or more, before moving on to another patch (Fig. 3b and $4 \mathrm{~b}$ ). As female water vole territories rarely overlap (Moorhouse and Macdonald 2008; Moorhouse et al. 2008), this pattern in female settlement may be partly explained by intrasexual competition, as at least 3 of our collared females arrived to share the same range of another before one of them moved away. Similar settlement behaviour has been demonstrated in juvenile water voles that were experimentally translocated in Scotland and was best explained by individuals searching for conspecifics at low density (Fisher et al. 2008). Further, Gundersen et al. (1999) suggest that sub-adult root voles (Microtus oeconomus) may be motivated to select patches with sexually mature individuals of the opposite sex. Social interactions such as these inevitably prolong the exploration phase, and this could explain the pattern of female movement in our study. Our observations, however, are based on a small sample of individuals whose locations were obtained over successive weeks. False negatives made up $15 \%$ of our data and collars failed for two individuals. More frequent monitoring is likely necessary to obtain a true picture of post-release settlement but as individuals continued to explore after 10 weeks following release, there is inevitably a trade-off between resources, animal welfare and obtaining an accurate picture of post-release movements and survival. 


\section{Conclusions and management implications}

Our study aimed to verify that translocating water voles in autumn should not be carried out due to a higher risk of overwinter mortality. Whilst we were unable to distinguish between dispersal and mortality, we found no evidence in support of this and suggest that translocations in autumn may be a feasible alternative to housing animals in captivity. Given our results, animals should be released into a vacant receptor site that supports a seasonal abundance of vegetative food and cover and is connected to suitable habitat to allow for post-release exploration and population expansion. For translocations involving small numbers of individuals, such as in our study, releasing into vacant habitats within established meta-populations is also advised to ensure the released population remains viable to ensure translocation success. As with our study, the release site and wider landscape should be mink free and under an ongoing mink control programme. Mink are capable of dispersing $>80 \mathrm{~km}$ (Melero et al. 2018) and without effective control at this scale, their incursion into receptor areas can result in the loss of the released population and translocation failure (Moorhouse et al. 2008).

The survival of juvenile/sub-adult voles released in autumn is particularly noteworthy, given that these are of the age class that will produce most of the following years' litters and thus establishment of the translocated population (Leuze 1976). Our separation of juveniles from adults during soft release may have contributed to this, and thus warrants further research in view of directing future guidance. Both dispersal and radio-collaring may have contributed to the loss of voles in both populations overwinter and the latter highlights the need for developing other, less invasive and more reliable methods for measuring movement of small mammals. Despite the potential risks of radio-collaring and limitations of sample size (weight restrictions and collar failure), the movement data showed voles travelled further in autumn than previously reported for individuals released in spring, but these distances were within the mean dispersal range observed in other studies (Telfer et al. 2003; Aars et al. 2006).

Whilst we believe that in situ habitat protection should be favoured over translocation, this is often not practical for large development projects and therefore alternative solutions must be employed. The main aim of ecological mitigation is to avoid negative impacts on affected populations, and for translocations, this necessitates the use of measures that will ensure the establishment of a viable population. Without follow-up monitoring, however, there is a considerable risk that these measures are not identified, leading to mitigation failures and a net loss in biodiversity (Treweek and Thompson 1997; Hill and Arnold 2012). Our study is an example of how mitigation measures from a live development project can be monitored and assessed to help provide guidance for practitioners. As with most live development sites, our study design was constrained by development timelines and resources which resulted in small sample sizes. As this will often be the case when 
monitoring mitigation outcomes, we advise that further studies are undertaken to confirm our findings and help build a robust evidence base that can direct future guidance.

\section{Acknowledgments}

We thank DP World, London for permitting this research and providing financial and logistical support. We are grateful to The Ecology Consultancy for providing equipment and the help of fieldwork assistants. We would also like to thank the Natural England licencing team, in particular, Hazel Carter, for supporting this research and Dr. Andrew Overall and Dr. Bryony Tolhurst for helpful guidance on data analysis in "R".

\section{Funding information}

DP World, London providing financial support for this study.

\section{Compliance with ethical standards}

Conflict of interest

The authors declare that they have no conflict of interest.

Ethical approval

All applicable international, national and/or institutional guidelines for the care and use of animals were followed (Natural England Licence 2016-22064-SCI-SCl). This study was conducted in parallel with an active development project and therefore was constrained in study design and by conditions stipulated under Natural England licence (2016-22064-SCI-SCI). Live capture and translocation followed best practice guidelines (Strachan et al. 2011; Dean et al. 2016). 


\section{References}

Aars J, Dallas JF, Piertney SB, Marshall F, Gow JL, Telfer S, Lambin X (2006) Widespread gene flow and high genetic variability in populations of water voles Arvicola terrestris in patchy habitats. Mol Ecol 15:1455-1466

Aiken LS, West SG (1991) Multiple regression: testing and interpreting interactions. Sage, Newbury Prk

Armstrong DP, Seddon PJ (2008) Directions in reintroduction biology. Trends Ecol Evol 23:20-25

Banks EM, Brooks RJ, Schnell J (1975) A radiotracking study of home range and activity of the brown lemming (Lemmus trimucronatus). J Mammal 56:888-901

Berger-Tal O, Saltz D (2014) Using the movement patterns of reintroduced animals to improve reintroduction success. Current Zool 60(4):515-526

Carter SP, Bright PW (2003) Reedbeds as refuges for water voles (Arvicola terrestris) from predation by introduced mink (Mustelavison). Biol Conserv 111:371376

Corner GW, Pearson EW (1972) A miniature 30-MHz collar transmitter for small mammals. J Wildl Manag 36:657-661

Dean M, Strachan R, Gow D, Andrews R (2016) The water vole mitigation handbook (The mammal society guidance series). Eds F. Mathews and P. Chanin. The Mammal Society, London

Firth D (1993) Bias reduction of maximum likelihood estimates. Biometrika 80:2738

Fischer J, Lindenmayer DB (2000) An assessment of the published results of animal relocations. Biol Conserv 96:1-11

Fisher DO, Lambin X, Yletyinen SM (2008) Experimental translocation of juvenile water voles in a Scottish lowland metapopulation. Popul Ecol 51(2):289-295 745

Gelling M, Zochowski W, Macdonald DW, Johnson A, Palmer M, Mathews F (2015) Leptospirosis acquisition following the reintroduction of wildlife. Vet Rec 177:440 748 
Germano JM, Bishop PJ (2008) Suitability of amphibians and reptiles for translocation. Conserv Biol 23(1):7-15

Germano JM, Field KJ, Griffiths RA, Clulow S, Foster J, Harding G, Swaisgood RR (2015) Mitigation-driven translocations: are we moving wildlife in the right direction? Front Ecol Environ 13(2): 100-105

Gow D, Andrews R, Smith DW (2012) Water vole mitigation guidance: Important updates for evidence-based good practice. In Practice Bulletin of the Chartered Institute of Ecology and Environmental Management 77:29-34

Gunderson G, Moe JA, Andreassen HP, Carlsen RG, Gundersen H (1999) Intersexual attraction in natal dispersing root voles Microtus oeconomus. Acta Theriologica (Warsz) 44:283-290

Hartley M, Sainsbury A (2017) Methods of disease risk analysis in wildlife translocations for conservation purposes. EcoHealth 14:S16-S29

Hill D, Arnold R (2012) Building the evidence base for ecological impact assessment and mitigation. J Appl Ecol 49:6-9

IUCN (World Conservation Union) (1998) Guidelines for re-introductions. IUCN/SSC Re-introduction Specialist Group, IUCN, Gland, Switzerland, and Cambridge, United Kingdom

IUCN/SSC (2013) Guidelines for reintroductions and other conservation translocations. Version 1.0. Gland, Switzerland: IUCN Species Survival Commission, viii $+57 p p$

Jefferies DJ,Morris PA,Mulleneux JE (1989) An enquiry into the changing status of the water vole Arvicola terrestris in Britain. Mammal Rev 19:111-131

Le Gouar P, Robert A, Choisy JP, Henriquet S, Lecuyer P, Tessier C, Sarrazin F (2008) Roles of survival and dispersal in reintroduction success of griffon vulture (Gyps fulvus). Ecol Appl 18:859-872

Leuze CCK (1976) Social behaviour and dispersion in the water vole, Arvicola terrestris. D. Phil, University of Aberdeen, Aberdeen

Mathews F, Moro D, Strachan R, Gelling M, Buller N (2006) Health surveillance in wildlife reintroductions. Biol Conserv 131:338-347 
Melero Y, Cornulier T, OliverMK, Lambin X (2018) Ecological traps for large-scale invasive species control: predicting settling rules by recolonising American mink post-culling. J Appl Ecol 55:1769-1779

Moehrenschlager A, Macdonald D (2003) Movement and survival parameters of translocated and resident swift foxes Vulpes velox. Anim Conserv 6(3):199-206

Moorhouse TP, Macdonald DW (2005) Indirect negative impacts of radio-collaring: sex ratio variation in water voles. J Appl Ecol 42(1): 791 91-98

Moorhouse TP, Macdonald DW (2008) What limits male range sizes at different population densities? Evidence from three populations of water voles. J Zool 274:395-402

Moorhouse TP, Gelling M, Macdonald DW (2009) Effects of habitat quality upon reintroduction success in water voles: evidence from a replicated experiment. Biol Conserv 142:53-60

Morgan KN, Tromborg CT (2007) Sources of stress in captivity. Appl Anim Behav Sci 102:262-302

Stoddart M (1970) Individual range, dispersion and dispersal in a population of water voles (Arvicola terrestris (L.)). J Anim Ecol 37:403-424

Strachan R, Jefferies DJ (1993) The water vole Arvicola terrestris in Britain 19891990: its distribution and changing status. The Vincent Wildlife Trust, London

Strachan C, Strachan R, Jefferies DJ (2000) Preliminary report on the changes in the water vole as shown by the National Surveys of 1989-1990 and 1996-1998. The Vincent Wildlife Trust, London

Strachan R, Moorhouse T, Gelling M (2011) Water vole conservation handbook, 3rd edn. The wildlife Conservation Unit, Abingdon

Telfer S, Holt A, Donaldson R, Lambin X (2001) Metapopulation processes and persistence in remnant water vole populations. Oikos 95: 31-42 814

Telfer S, Piertney SB, Dallas JF, StewartWA,Marshall F, Gow J, Lambin X (2003) Parentage assignment reveals widespread and large-scale dispersal in water voles. Mol Ecol 12:1939-1951 
Treweek J, Thompson S (1997) A review of ecological mitigation measures in UK environmental statements with respect to sustainable development. Int J Sust Dev World 4(1):40-50

Webster AB, Brooks RJ (1980) Effects of radiotransmitters on the meadow vole, Microtus pennsylvanicus. Can J Zool 58:997-1001 